\title{
Walking Distance Perception in Jakarta MRT Station Area*
}

\author{
Alfaizs Vi Afkara \\ Civil Engineering Department \\ University of Indonesia \\ Depok, Indonesia \\ alfaizsva@gmail.com
}

\author{
Andyka Kusuma \\ Civil Engineering Department \\ University of Indonesia \\ Depok, Indonesia \\ andyka.k@eng.ui.ac.id
}

\begin{abstract}
The interest of the community, especially MRT users to walk at the beginning or end of the journey to the MRT station is relatively low. The purpose of this study was to recognize the effect of changed preference attributes that affect the likelihood and distance of someone who will choose to walk compared to BRT and motorcycle taxi modes at the beginning or end of their journey. Data obtained using stated preference techniques and were analyzed by discrete choice analysis using a binomial logit model approach with 2 schemes, walking with BRT and walking with motorcycle taxi. The walking distance perception between men and women will choose to walk compared to others alternative mode when the distance to MRT stations are 629 meters and 593 meters respectively and the walking distance perception, when compared to the area between the office area and residence area are 689 meters and 547 meters.
\end{abstract}

Kerwords: perception, walking distance, MRT station, stated preference, discrete choice, difference binomial logit model

\section{INTRODUCTION}

In Metropolitan cities such as Jakarta, which is the capital city of Indonesia as well as the center of the national economy and politics, population mobility is highly dependent on mass transportation modes such as Bus Rapid Transit (Transjakarta), Commuter Line trains, Mass Rapid Transit, and others. Some people must choose several other modes of transportation to reach the mass transportation facilities at the beginning or end of their journey, such as walking, cycling, using a motorcycle taxi, or using private vehicles. Of course, the selection is not only influenced by the mileage variables. Therefore, this study will identify what factors will influence the choice of walking mode at the beginning or end of the trip.

The subjects of this study were respondents who used Mass Rapid Transit (MRT) in Jakarta at the beginning or end of their trip. The selection of MRT stations as the focus of research involving walking modes because MRT is relatively new in Jakarta. Therefore, it is still not too late to plan facilities to walk around the MRT station which favors MRT passengers who use walking mode at the beginning or end of their journey. For the future development of the MRT and the culture of walking for the community from the start of the MRT operation. With the existence of walking modes that are increasingly entrenched in our society, it is expected to provide many positive things for the community and the government.

\section{WALKING DistANCE}

Walking distance is the distance that people can walk on a trip or the average distance of people walking to access the transit point to a point in a certain area. There has been a lot of research on walking accessibility and public transportation which discusses the ideal walking distance that people can travel.

Walking Distance to and from Light-Rail Transit Stations, guidelines for walking distance to the zone around local stations, transit stations, and CBD are as follows, 700 meters for the radius of the zone around the local station, 700 meters for the radius of the zone around the transit station, 400 meters for the radius of the zone around the station near the office, and 900 meters for the radius of the zone around the station near the settlement [1].

Modeling Walking Access to Public Transport Terminals: Case Study of Singapore Mass Rapid Transit, the average distance traveled by people to and from the MRT station is 1045.7 meters [2]. The Study of Pedestrian Access to Rail Transit Stations Based on the KLP Model, the standard distance of walking to the public transport station ranges from 472 meters to 862 meters [3]. Pedestrian Perception at the End of the Final Trip, from the collected data, the average distance and the farthest distance are 1,225 meters and 2,100 meters respectively [4].

\section{Discrete CHOICE}

Before Akiva and Leman (1985) in his book "Discrete Choice Analysis: Theory and Application to Travel Demand" emphasize this model more on the analysis of user choice to maximize satisfaction in making various choices and deciding which mode of transportation has the highest satisfaction value (highest utility) [5]. The procedure of this model begins with determining parameter values (regression coefficients) of a satisfaction function that is influenced by several independent variables. The model approach taken in this study was carried out using the Discrete Choice Model.

To compare between the two choices of transportation modes offered, it can be used to estimate linear functions, namely the binomial logit model difference with parameters that can be assumed to be linear [6]. The function equation model is:

This study is funded through the PITTA grant scheme No. ND 162/UN2.R3.1/PPM.00/2019. 


$$
U_{i}=\beta_{i 0}+\beta_{i 1} X_{i 1}+\beta_{i 2} X_{i 2}+\ldots+\beta_{i k} X_{i k}
$$

Where Ui is the utility function of mode i, $\beta \mathrm{ik}$ is the kvariable parameter of mode $i$, and Xik is the k-variable of mode i. The discrete selection model is generally expressed as an opportunity for each individual to choose a choice as a function of the socio-economic characteristics and attractiveness of that choice [6]. Opportunities for choosing the intended mode as in (2).

$$
P_{i}=1 /\left[1+e^{-(U i-U j)}\right]
$$

\section{DATA AND METHODS}

This research is a case study for pedestrians in the MRT station area, specifically for Jakarta MRT users who walk from or to the MRT station. Data collection locations are carried out at 6 Jakarta MRT stations. Three of them are in the office area, namely the MRT Bundaran HI, Duku Atas and Bendungan Hilir Stations were taken in the evening time. The three other in the residential areas, namely the Haji Nawi, Cipete Raya and Fatmawati MRT stations were taken in the day time. MRT user samples were taken randomly with a total of 210 respondents with the majority of respondents aged 21-40 years to travel to work and the proportion of men and women was $58 \%$ and $42 \%$.

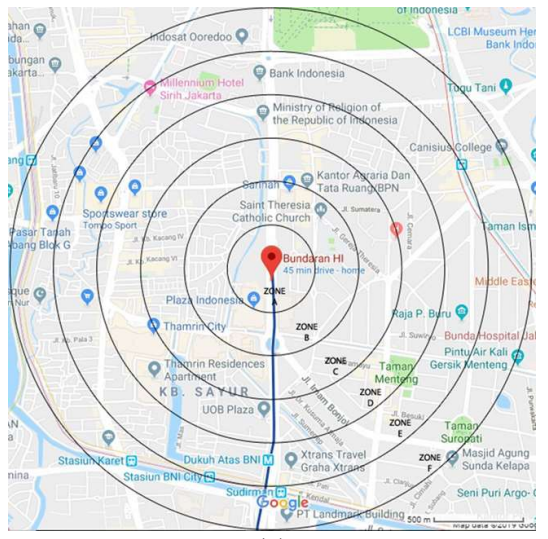

(a)

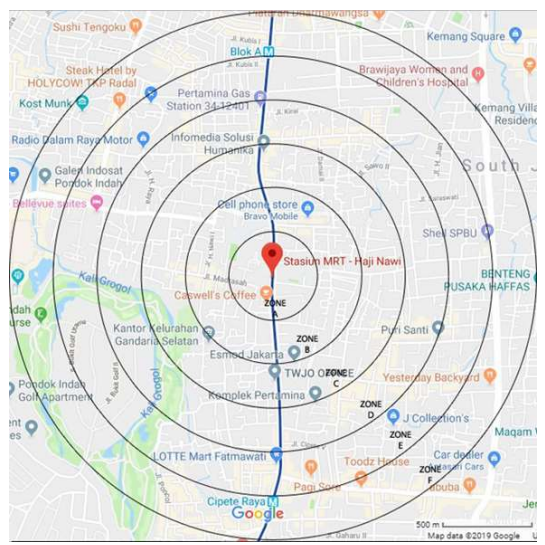

(b)

Fig. 1. Radius zone of distance at a) Bundaran HI Station and b) Haji Nawi Station.

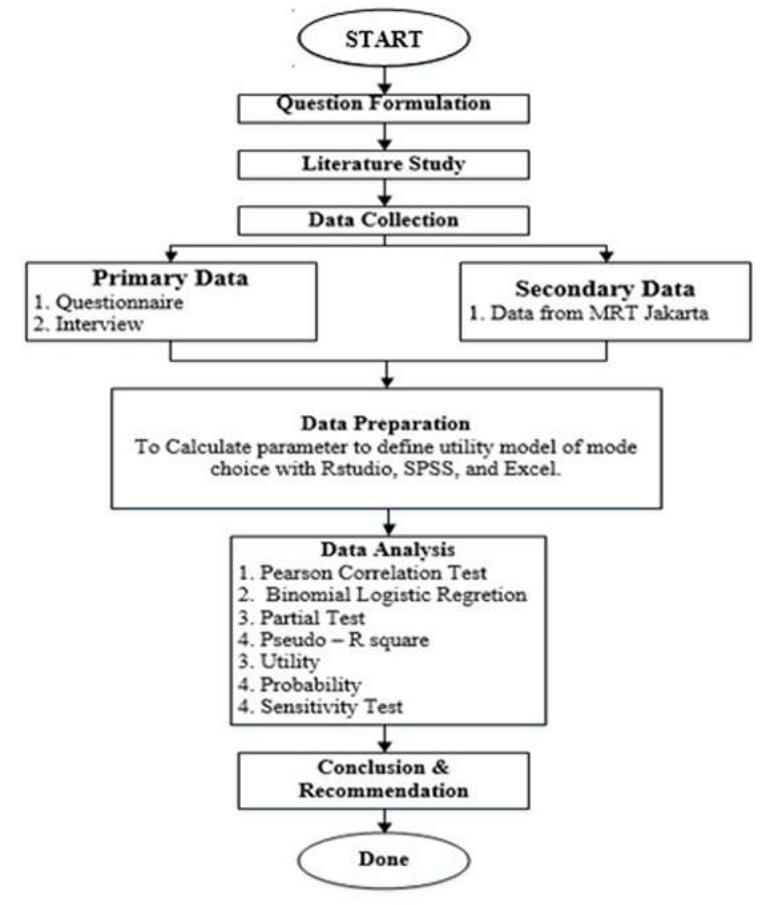

Fig. 2. Research Framework.

Research framework based on Fig. 2 above, the research start by formulated quastions, literature study and data collection using survey and interview questionnaire techniques. The questionnaire was designed using the stated preference method for scheme 1 and scheme 2. Scheme 1 was to compare the interest in walking with BRT, where BRT mentioned here include Transjakarta in the corridor, Tranjakarta Feeder (non-corridor), and Jak-Lingko (integrated mode). Scheme 2 was to compare the interest in walking with a motorcycle taxi, where motorcycle taxi mentioned here include online and conventional motorcycle taxi.

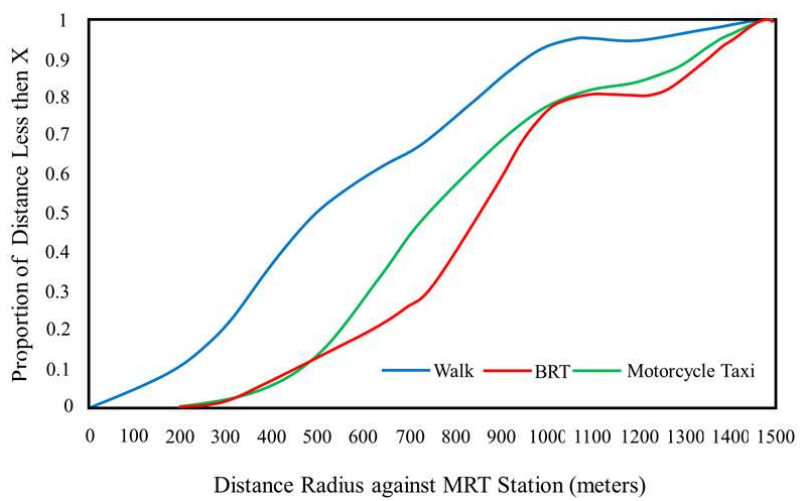

Fig. 3. The proportion of Walking Less Than X.

Obtained 1890 response conditions preferences from 210 respondents, with details of scheme 1 and scheme 2, respectively 684 responses and 1206 responses. Where the responses that chose to use walking mode, BRT, and motorbike motorbikes were 724 responses, 459 responses and 707 responses with the proportion as in Fig. 3. 


\section{ANALYSIS}

Start from the data collection phase, it has been grouped into two schemes, so that the next step will be analyzed modal choice for each scheme using package maxLik (maximum Likelihood package) in program R. After testing several models, the best function model with the value is obtained. The biggest P-seudo R2. Follow by the best function model for scheme 1 and scheme 2 :

\section{A. Scheme 1:(Walking-BRT)}

TABLE I. PARAMETER Estimation For WALK SELECTION MOdEL SCHEME 1

\begin{tabular}{|l|l|l|l|l|l|}
\hline Parameter & \multicolumn{1}{|c|}{ B } & \multicolumn{1}{|c|}{ S.E } & \multicolumn{1}{|l}{ Z value } & $\operatorname{Pr}(>|\mathrm{Z}|)$ & $\operatorname{Exp(B)}$ \\
\hline $\begin{array}{l}\text { (Intercept) } \\
* * *\end{array}$ & $\mathbf{- 5 . 7 7 6}$ & $\mathbf{0 . 6 4 2}$ & $\mathbf{- 8 . 9 9 8}$ & $<\mathbf{2 e - 1 6}$ & $\mathbf{0 . 0 0 3}$ \\
\hline Gender & 0.325 & 0.229 & 1.417 & 0.1565 & 1.384 \\
\hline Distance** & -0.001 & 0.000 & -2.702 & 0.0069 & 0.999 \\
\hline Time*** & -0.208 & 0.029 & -7.268 & $3.64 \mathrm{E}-13$ & 0.812 \\
\hline Fare*** & 0.001 & 0.000 & 11.951 & $<2 \mathrm{e}-16$ & 1.001 \\
\hline Log-likelihood at maximum, Log L & 256.200 \\
\hline
\end{tabular}

TABLE I above serve the comparison of the final likelihood value with initial likelihood is represented by the Pseudo-R2 value of 0.3947 states that $39.47 \%$ of the function model of scheme 1 is influenced by gender attributes, the radius of distance, time difference, and alternative mode fares and the others are influenced by other variables. So, the utility function model is obtained for scheme 1 as in (3).

$U_{W}-U_{B R T}=-5,776+0,325($ Gender $)-0,001$ (Dist) $0,208\left(d_{\text {Time }}\right)+0,001$ (Fare $)$

Some interpretations of the utility model function scheme 1 above:

- To access the MRT station, the BRT mode is more desirable than the walking mode.

- Men are more likely to choose to walk compared to women.

- The difference in travel time on walking with BRT greatly influences the choice of walking mode. The more negative the difference, the greater the interest in choosing to walk rather than using BRT.

From the utility function model, the sensitivity of interest in male and female walking interest was tested when the standard BRT fare was Rp. 3,500 due to changes indifference of travel time.

From Fig. 4a) above, about the four groups of distance radius, the probability of women choosing to walk will keep existing when walking time is 18 minutes longer than using BRT. While for a condition where a woman will decide to walk for a distance of $250 \mathrm{~m}$ occurs when walking time is 4 minutes faster than using BRT, for a $500 \mathrm{~m}$ distance radius occurs when walking time is 6 minutes faster than using $\mathrm{BRT}$, to a $750 \mathrm{~m}$ distance radius occurs when walking is 7 minutes faster than using BRT, for a $1,000 \mathrm{~m}$ distance radius occurs when the walking time is 8 minutes faster than using $\mathrm{BRT}$, for a distance radius of $1,250 \mathrm{~m}$ occurs when the walking time is 10 minutes faster than use BRT, and for a distance radius of $1,500 \mathrm{~m}$ occurs when the walking time is 11 minutes faster than using BRT. Meanwhile, women are more likely to walk on conditions with 33 minutes faster on walking for the four groups of distance radius.

From Fig. 4b) above, about the four groups of distance radius, the probability of men choosing to walk will keep existing when walking time is for up to 19 minutes from using BRT. While the condition where a man will begin to tend to decide to walk for a distance of $250 \mathrm{~m}$ occurs when the walking time is 3 minutes faster than using BRT, for a $500 \mathrm{~m}$ distance radius occurs when walking time is 4 minutes faster than using BRT, to a $750 \mathrm{~m}$ distance radius occurs when the walking time is 5 minutes faster than using BRT, for a $1,000 \mathrm{~m}$ distance radius occurs when the walking time is 7 minutes faster than using BRT, for a distance radius of $1,250 \mathrm{~m}$ occurs when the walking time is 8 minutes faster than use BRT, and for a distance radius of $1,500 \mathrm{~m}$ it occurs when 10 minutes of walking is faster than using BRT. Meanwhile, men are more likely to walk on conditions with 32 minutes faster on walking for the four groups of distance radius.

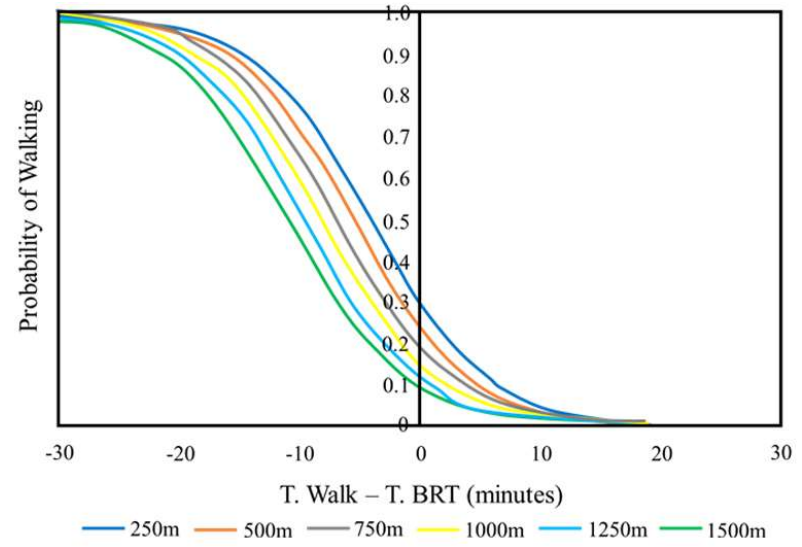

(a)

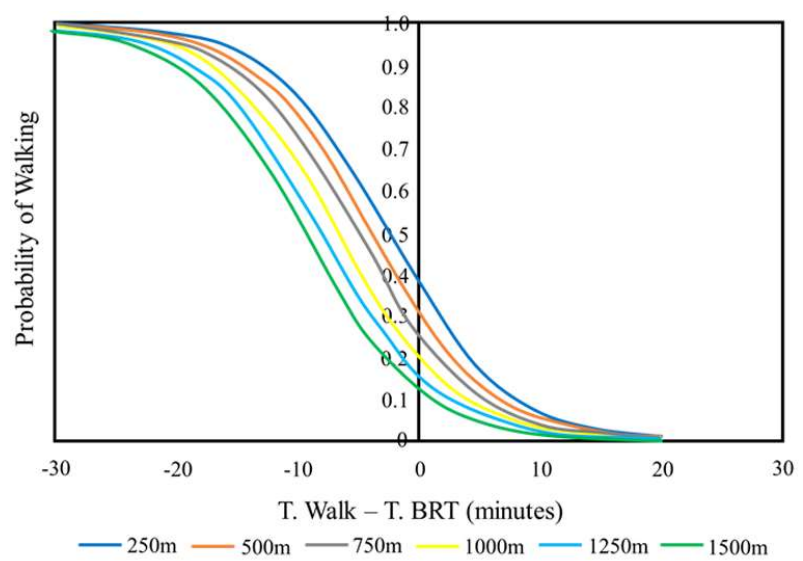

(b)

Fig. 4. Men's Walking Probability for a) woman and b) man when BRT Fare was Rp. 3,500 for Change in Difference of Travel Time Scheme 1. 


\section{B. Scheme 2:(Walking-Motorcycle Taxi)}

TABLE II. PARAMETER ESTIMATION For WALK SElection Model SCHEME 2

\begin{tabular}{|c|c|c|c|c|c|}
\hline Parameter & B & S.E & $Z$ value & $\operatorname{Pr}(>|Z|)$ & $\operatorname{Exp}(B)$ \\
\hline $\begin{array}{l}\text { (Intercept) } \\
* * *\end{array}$ & -14.210 & 1.035 & -13.731 & $<2 \mathrm{e}-16$ & 0.000 \\
\hline Gender & -0.016 & 0.159 & -0.103 & 0.918 & 0.984 \\
\hline Distance $^{* *}$ & -0.002 & 0.000 & -5.917 & 0.000 & 0.998 \\
\hline Time*** & -0.183 & 0.020 & -9.284 & $<2 \mathrm{e}-16$ & 0.833 \\
\hline Fare $* * *$ & 0.002 & 0.000 & 15.201 & $<2 \mathrm{e}-16$ & 1.002 \\
\hline \multicolumn{5}{|c|}{ Log-likelihood at maximum, $\log \mathrm{L}$} & $\begin{array}{l}506.00 \\
40\end{array}$ \\
\hline \multicolumn{5}{|c|}{ Log-likelihood for only constant, $\operatorname{LogLO}$} & $\begin{array}{l}835.93 \\
60\end{array}$ \\
\hline \multicolumn{5}{|c|}{ Pseudo-R2 (Mc. Fadden) } & 0.3947 \\
\hline
\end{tabular}

TABLE II above serve the comparison of the final likelihood value with initial likelihood represented by the Pseudo-R2 value of 0.4596 states that $45.96 \%$ of the function model of scheme 2 is influenced by gender attributes, distance radius, time difference, and alternative mode fares and the rest is influenced by other variables. So that the utility function model is obtained for scheme 2 as in (4).

$U_{W}-U_{M c T}=-14,210-0,016($ Gender $)-0,002($ Dist $)-$

$0,183\left(d_{\text {Time }}\right)+0.002$ (Fare)

Some interpretations of the schema 2 utility function model above:

- To access the MRT station, motorcycle taxi modes are more popular than walking modes.

- Women are more likely to choose to walk compared to men.

- The difference in travel time on foot with motorcycle taxi travel time also greatly affects the choice of walking mode. The more negative the difference, the greater the interest in choosing to walk rather than using a motorcycle taxi.

From the utility function model, a sensitivity test of interest in male and female walking was carried out when the standard motorcycle taxi fare was Rp. 10,000, due to changes in the difference in travel time.

It appears from Fig. 5a) and Fig. 5b) below, that there is no difference in the change in attributes of the probability of walking compared to motorcycle taxis between women and men in the same conditions. So, the probability of women and men alike choosing to walk will remain until 42 minutes have passed from using a motorcycle taxi. While for a situation where a woman and a man will begin to tend to decide to walk for a distance of $250 \mathrm{~m}$ occurs when 17 minutes walk longer than using a motorcycle taxi, for a 500 $\mathrm{m}$ distance radius occurs when walking time is 14 minutes longer than using a motorcycle taxi, for a $750 \mathrm{~m}$ distance radius occurs when walking time is 11 minutes longer than using a motorcycle taxi, for a 1,000 $\mathrm{m}$ distance radius occurs when the walking time is 8 minutes longer than using a motorcycle taxi, for a distance radius of $1,250 \mathrm{~m}$ occurs when the walking time is longer 5 minutes from using a motorcycle taxi, and for a distance radius of $1,500 \mathrm{~m}$ it occurs when the walking time is 3 minutes longer than using a motorcycle taxi. Meanwhile, women and men will most likely walk on conditions with a difference of 23 minutes faster walking for the four groups of distance radius.

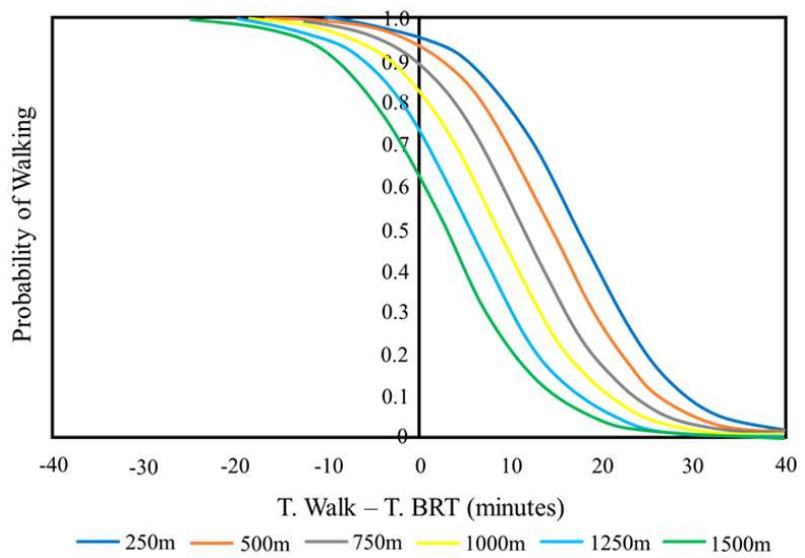

(a)

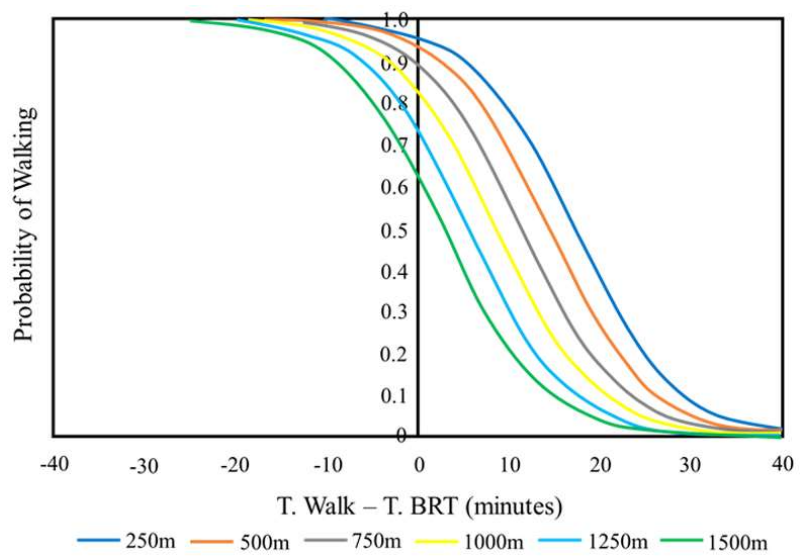

(b)

Fig. 5. Probability of Walking for a) woman and b) man when Motorcycle Taxi Fare was Rp.10,000 for Change in Difference of Travel Time Scheme 2.

\section{WALKING Distance PERCEPTION}

In describing the perception of the distance a person chooses to walk is compared with using other modes analyzed by two considerations, namely walking distance based on gender and functional area of each scheme.

From Fig. 6a) above, the distance between women will choose to walk in scheme 1 and scheme 2 is 455 meters and 671 meters respectively, so that the average women's walking distance from the two schemes is 593 meters. Whereas for men in scheme 1 and scheme 2 respectively are 558 meters and 669 meters with the average men's walking distance from the two schemes is 629 meters. The results explained that men can walk farther than women.

Whereas from Fig. 6b) above, it is obtained that the distance of someone will choose to walk in an office area in scheme 1 and scheme 2 is 537 meters and 775 meters respectively so that the average walking distance in the office 
area of the two schemes is 689 meters. Whereas in residential areas in scheme 1 and scheme 2 are 492 meters and 578 meters respectively, the average walking distance in the residential area of the two schemes is 547 meters.

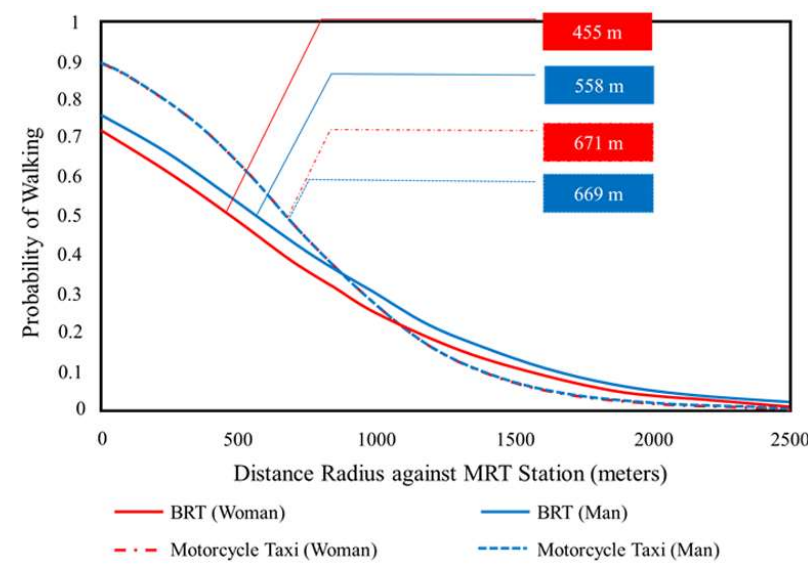

(a)

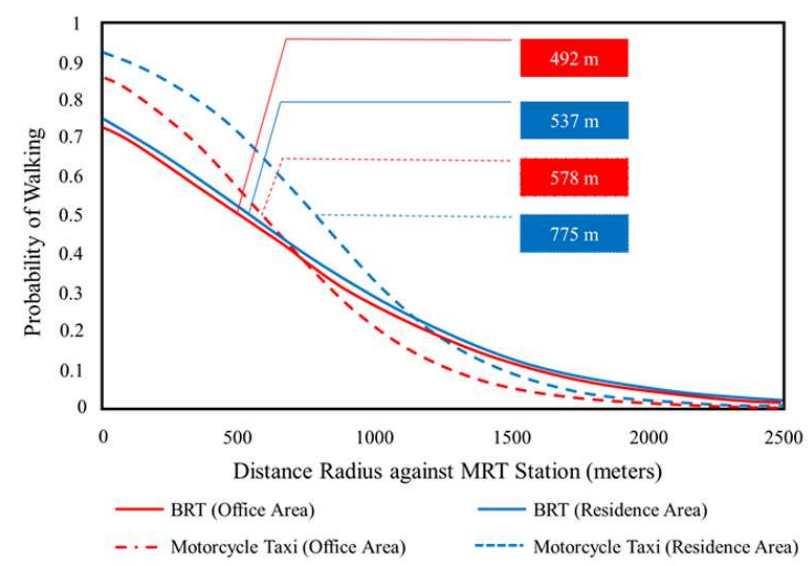

(b)

Fig. 6. Probability of Walking based on a) gender and b) functional zone due to Changes in Radius Distance to MRT Station.

These results explain that in an office area the average person can walk farther than those in residential areas. This can occur because the facilities for walking in office areas are adequate with a good level of comfort. Whereas in residential areas, sidewalk and crossing facilities are inadequate and the level of comfort is relatively lacking.

From the two calculations above, the average distance of a person chooses to walk to the MRT station if it does not consider the gender and functional area is 618 meters.

\section{CONCLUSIONS}

1) The attributes that influence the walking selection than BRT or motorcycle taxi are gender, the difference of travel time, distance and alternative mode fare.

2) Men will begin to choose to walk at a distance of 629 meters, while women will begin to choose to walk at a distance of 593 meters.
3) Someone in the office area will begin to choose to walk at a distance of 689 meters, while in the residential area will begin to choose to walk at a shorter distance of 547 meters.

4) The average distance a person choose to walk is 618 meters.

\section{VIII.RECOMMENDATIONS}

Based on the research that has been done and the analysis described above, the suggestion that is suitable for these conditions is to improve pedestrian facilities in the area of the main MRT station in the residential area. Whereas for the next research which is similar can be suggested as follows:

1) Using the revealed preference method to get the perception of the actual walk of the people heading to or from the MRT station. So that the distance is not categorized based on the radius of the MRT station.

2) If using the revealed preference method, it is recommended to use a larger number of samples.

3) Consider the characteristics of the pedestrian pathway in the MRT station area as a factor that influences the walking interest.

4) Using a multinomial logistic regression analysis model to determine walking interest compared to several alternative modes.

\section{ACKNOWLEDGMENT}

We want to give our high appreciation for Indonesia University for providing an opportunity in studying walking distance perception in Jakarta MRT Station area. This study is funded through the PITTA grant scheme No. ND162/UN2.R3.1/PPM.00/2019.

\section{REFERENCES}

[1] Sullivan, S.O. dan Morrall, J, Walking Distances to and from LightRail Transit Stations, Transportation Research Record: Journal of the Transportation Research Board, pp. 1538: 19-26, 1996.

[2] Olszewski, P. dan Wibowo, S., Using Equivalent Walking Distance to Assess Pedestrian Accessibility to Transit Stations in Singapore. Transportation Research Record: Transit: Planning, Management and Maintenance, Technology, Marketing, and Fare Policy, and Capacity and Quality of Service, pp. 1927: 38-45, 2005.

[3] Yang, R., Yan, H., Xiong, W. and Liu, T., The Study of Pedestrian Accessibility to Rail Transit Stations Based on KLP Model, ProcediaSocial and Behavioral Sciences, pp. 714-722, 2013.

[4] Kusuma, A, dan Arisyi, D.G., Pedestrian Perception at the End of a Daily Journey (in Indonesian), Indonesia University. Depok, 2017.

[5] Ben-Akiva, M., and S. Lerman. 1985. Discrete choice analysis: Theory and application to travel demand. Cambridge, MA: MIT Press.

[6] Tamin, O.Z., Transportation planning and modeling . Bandung: ITB Publisher, 2000. 